\title{
Correlates of Parental Choice of Child Discipline Methods in Ghana: A Multilevel Modeling Approach
}

\author{
Stephen Kwaku Amoah', Ezekiel Nii Noye Nortey², Abukari Alhassan³ \\ ${ }^{1}$ Ghana Statistical Service, Accra, Ghana \\ ${ }^{2}$ Department of Statistics, University of Ghana, Legon, Accra, Ghana \\ ${ }^{3}$ Department of Statistics, University for Development Studies, UE, Novrango Campus, Tamale, Ghana \\ Email: stephen.amoah@statsghana.gov.gh, ennortey@ug.edu.gh, hassi1972@yahoo.com
}

How to cite this paper: Amoah, S.K., Nortey, E.N.N. and Alhassan, A. (2020) Correlates of Parental Choice of Child Discipline Methods in Ghana: A Multilevel Modeling Approach. Open Journal of Applied Sciences, 10, 78-99.

https://doi.org/10.4236/ojapps.2020.103007

Received: December 11, 2019

Accepted: March 16, 2020

Published: March 19, 2020

Copyright $\odot 2020$ by author(s) and Scientific Research Publishing Inc. This work is licensed under the Creative Commons Attribution International License (CC BY 4.0).

http://creativecommons.org/licenses/by/4.0/

\begin{abstract}
This study applied multilevel modeling to investigate the impact of observed predictors and different levels or groups that households belong, on parents' choice of discipline methods using data from 8156 households derived from a nationwide survey by the Ghana Statistical Service (GSS) in 2011. The aim of the study is to provide in-depth information on why parents choose particular discipline methods as corrective measures to reduce unwanted child behaviour in the present and to increase desirable ones in the future. The results of the study show that, religion and age-group of household heads have significant effect on household's likelihood to choose physical discipline methods whereas the wealth index of a household and ethnicity of the household head, have significant effect on households' likelihood to choose non-physical and psychological aggression methods. The results further show significant contextual effect on the differences in choices of parents at the household and regional levels. The choice of physical discipline methods by parents was consistent across households and regional levels unlike non-physical and psychological aggression methods whose application varied across the regions. Households in the Northern, Eastern and Volta regions mostly chose to apply physical discipline methods whereas in the Upper West, Western and Northern regions the most chosen discipline methods were non-physical discipline methods. Psychological aggression discipline methods were predominantly applied in the Upper East, Central and Northern regions of the country.
\end{abstract}

\section{Keywords}

Child Discipline, Physical Discipline, Non-Physical Discipline, Psychological Aggression Discipline, Multilevel Multinomial Logit Model, Hierarchical 
Structured Data, Nested Data

\section{Introduction}

Child discipline is the process of teaching children what type of behavior is acceptable and what type is not acceptable. While some experts are of the view that discipline, in all instances is harmful to children as it may produce an inhibited or neurotic child [1], others believe that discipline is a critical aspect of childrearing [2]. For this group of experts, without discipline, children tend to lack the tools necessary to handle relationships and challenges in life such as self-discipline, respect for others, and the ability to cooperate with peers.

Research shows that many of the methods parents use to discipline their children have different effects on the child's physical, behavioral, and mental well-being. Children of parents who used corporal punishment as a discipline technique tend to use corporal punishment as a discipline technique with their own children [3].

A number of related studies on the different types of discipline and how frequently the different types are used have been conducted [3]. In their study of the relationship between harsh verbal and physical discipline and children's internal and external problems, [4] concluded that the use of harsh discipline and positive parenting was transgenerational. [5], studying the different types of discipline with young children aged $1-3$, and the changes in punishment methods that occur between those ages, found how discipline practices change and what discipline techniques parents use and how often. Bates et al. 2003, in their study of adolescents' attitudes about physical punishment, found that families where the parents were spanked had the likelihood they will use spanking as a method of discipline.

Literature review indicates that, globally there are measurement issues with respect to definitions and recognition of child discipline, as these vary by culture and country [3]. The different kinds of discipline methods in use included, physical discipline methods where physical force is applied, non-physical discipline methods where parents explained why something was wrong, and psychological aggression discipline methods which involves yelling at, or calling the child derogatory names. World report on violence against children, shows that there is scanty population based data in most countries. However, international studies on child discipline like the series of the Multiple Indicator Cluster Surveys (MICS) which provide information on the prevalence of violent and non-violent discipline methods applied in homes, and studies by an international project investigating violence toward women and children, have examined factors related to violent behavior, and how these factors vary across cultures [6].

Global findings show that in Chile, Brazil, Philippines and Egypt, application of physical discipline methods like spanking is more common. Non-physical 
discipline methods like yelling are frequent in almost all cultures. Discipline methods like time-out, taking privileges away which are non-physical are less common in developing countries [7]. These studies reveal that nearly all parents yell and spanking is common in country studies. Records also show that currently, only 60 out of 193 countries belonging to the United Nations have fully prohibited corporal punishment at home. In schools, the level of prohibition is higher, with about 130 countries making it fully or partially illegal [8].

Child discipline studies in Ghana are limited. Until recently, when the GSS conducted MICS 3 and MICS 4 in 2006 and 2011 respectively [9] [10], limited studies on child discipline in Ghana focused on children in schools. The MICS is a nationally representative internationally comparable household survey implemented to examine protective and risk factors of child development in developing countries around the world. The MICS 3 and MICS 4 surveys described the situation of children in Ghana with reference to the nutrition, parenting, discipline and violence and the home environment. Like the other studies on child discipline, the two surveys used only simple descriptive analysis of the situation without considering the context in which the data was collected. The MICS 3 and 4 finding indicated a worrying trend of increased rise in the use of physical discipline methods. In Africa, even though Ghana was the first country to endorse the 1989 UN convention on children's rights' [11], it has been argued that certain social facts such as poverty and the image of childhood in Ghana make the ratification of the $\mathrm{UN}$ convention more as rhetoric than a reality.

According to UNICEF Report in 2014, children in Ghana experience the 7th highest rate of violent discipline, with over $90 \%$ of children surveyed having experienced violent discipline in the preceding month compared to 33 low and middle income countries [12]. A study by Twum-Danso in 2010, concluded that discipline is seen as an inherent part of parental love and care, and highly valued by adults and children [13] [14]. "There is greater tolerance of violence in the home than in schools with strong emphasis on using "proportional" violence to build the moral character of a child". Also, in their study, titled "Better discipline for Ghana's children", Danvers and Schley in 2015, concluded that the use of physical discipline in Ghana, is "steeped in religious, cultural, social and legal foundation" [15]. Most of these studies in their analysis overlooked the hierarchical structure of the collected data even though complex survey designs were used in the data collection as in the case of MICS 3 and 4.

In view of the above, the objective of this study is to deepen the investigation on what make parents apply particular discipline methods on their children and in addition propose a probabilistic model based on the MICS 4 dataset to answer the following questions: 1) What are the chances of households choosing specific types of discipline methods? 2) Does the type of discipline method chosen vary across the regions in Ghana? 3) Does the choice of discipline method dependent on particular variables? 4) Do specific variables influence the choice of particular discipline methods in different ways? 5) Are there regional effects on choice of particular types of discipline method? The study also sought to draw conclusions 
and make recommendations.

The reason for this study therefore, is to explore the factors that affect parent's or caregivers choice of particular discipline methods in the upbringing of children taking into consideration external social effects on the parents and their individual characteristics. This study has great significance as its finding will benefit society considering that child discipline practices play an important role in child development. The appropriate raising of children, who are the future leaders and reducing violence against children, justifies the need for positive child discipline methods in the rearing of children. The application of findings of this study will lead to bringing up children who will be responsible for themselves when they are older and demonstrate desirable behaviors in the future. Counselors will be guided on what should be emphasized by parents and caregivers to appropriately bring up children in their care to become responsible adults. For researchers, this study should help them uncover how various factors at play influence parent's choice of discipline methods and how to simultaneously investigate relationships within and between hierarchical levels of grouped data making it more efficient at accounting for variance among variables at different levels than other existing analyses.

\section{Materials and Methods}

\subsection{Data}

The dataset used in this study was obtained from the child discipline module in MICS 4 conducted in 2011 by GSS. The survey sample was obtained using a 2-stage stratified cluster sampling with the first stage involving selection of primary sampling units from Ghana's 2010 Population and Housing Census and the second stage sampling of households from the selected clusters in the first stage. The data structure comprised of three levels: households as the level-1, type of area of household as level-2, and region of household as level-3. Parents' responses to multiple hypothetical questions involving child misbehaviour were the measure of discipline responses. Households with at least a child aged 2 - 14 were asked structured questions on child discipline and how discipline was administered in response to, the perceived misbehaviour by the child were recorded. A five level response variable was identified after analysis of the household responses. The following characteristics of the selected households were also collected: Sex of household head, religious affiliation of head, educational level of head, ethnicity of household head, and wealth index of household, number of children aged 2 - 14 in household, household size, locality and region of household.

\subsection{The Multinomial Logit Model}

Because our response variable (dependent variable) has a multinomial outcome with five unordered categories, the multinomial logit model was considered the appropriate analytic procedure for the dataset. The five unordered categories 
are: 1) households that mostly chose to apply physical discipline methods, 2) households that mostly chose to apply non-physical discipline methods, 3) households that mostly chose to apply psychological aggression discipline methods, 4) households that mostly chose to apply both non-physical and psychological aggression methods and 5) households that mostly chose to apply randomly any of methods-no specific discipline method. For a multinomial categorical outcome, we assumed a multinomial probability distribution and application of a logit link function.

Denoting the total number of outcome categorization as $C$, with each individual category indexed by $c$ such that the probability of being in the cth outcome category $P(Y=c)$ is $\pi_{c}$ where $(c=1,2, \cdots, C)$. The cumulative probability of each possible outcome $\left(\pi_{1}, \pi_{2}, \cdots, \pi_{c}\right)$ was expressed such that their sum is one. Using one of the categories as the reference category we estimated $C-1$ equations. The probability of membership in each of the categories was compared against the probability of being in the reference category. Using the logit link function we transformed the outcome scores of the model into an unobserved continuous variable $\eta_{c}$ that described the log odds of being in a particular category $c$ in contrast to the reference category with a variance $\operatorname{Var}\left(Y_{c} / \pi_{c}=\pi_{c}\left(1-\pi_{c}\right)\right)$.

Using the multinomial logistics regression model to predict the odds of individual $i$ in group $j$ being in outcome category $c$ relative to outcome $C$ (reference category) and applying to the set of $q$ predictors, we defined

$$
\eta_{c i j}=\log \left(\frac{\pi_{c i j}}{\pi_{C i j}}\right)=\beta_{0 j c}+\beta_{1 j c} X_{1 i j}+\beta_{2 j c} X_{2 i j}+\cdots+\beta_{q j c} X_{q i j}
$$

for two levels (individual household level-1and regional level-3. Level-2, area of household indicated an ICC of near zero indicating no influence of the level on responses-results Table not shown) where there is no separate residual variance term at level-1 because the variance is dependent upon the mean and is also set to a scale factor of 1 .

Summarizing Equation (1) to link the expected values of the outcome to the predicted values of $\eta_{c i j}$ we obtained:

$$
\eta_{c i j}=\log \left(\frac{\pi_{c i j}}{\pi_{C i j}}\right)=\beta_{0 j(c)}+\sum_{q=1}^{Q} \beta_{q j(c)} X_{q i j}
$$

\subsection{Computing Predicted Probabilities}

For the dependent variable with $C$ categories, we calculated $C-1 \log$ odds equations using

$$
\pi_{c i j}=\frac{\exp \left(\eta_{c i j}\right)}{1+\sum_{c=1}^{C-1} \exp \left(\eta_{c i j}\right)}
$$

where $\eta_{c i j}$ is the value of the linear component for specific values of the predictors if there are any in the model. For the reference category the value of $\eta_{c i j}$ 
is 0 and $\exp (0)=1$; the $\log$ odds are therefore $0[\log (1)=0]$, and the odds ratio is $1\left(e^{0}=1\right)$. The probability of being in the reference category is then

$$
\pi_{c i j}=\frac{1}{1+\sum_{c-1}^{C-1} \exp \left(\eta_{c i j}\right)}
$$

\subsection{Building the Multilevel Multinomial Response Model}

The multilevel multinomial logistic regression model was applied to predict the probability of being in one of the categories taking into consideration the effects of the predictors. This model addresses the problem of dependencies between individual observations which occurs in survey studies where the sample is not taken randomly but instead from cluster sampling from geographical areas. Since our outcome is nominal, we considered the logit link function. The following steps were used to build the best fitting multinomial model for the dataset. First an unconditional model M1 with no predictors was determined. This was followed by determining the conditional model M2 (M1 plus three predictors). The next determination, was the conditional model M3 (M2 plus two additional predictors) and finally a conditional model M4 made up of model M3 plus two more predictors.

\subsection{Assessing the Performance of the Model}

To determine how close our model's predictions were to the actual observed outcomes in the sample test cases, a classification test was conducted to determine the classification power of the model. The overall classification percentage of the model was first determined with no predictors followed by a final classification determination rates with the inclusion of all predictors.

\section{Results and Discussions}

\subsection{Background Information and Descriptive Analysis}

Descriptive analysis of the data (Table 1) shows an overall response profile, of $23.0 \%$ of households in the sample chose to apply non-physical methods, $26.4 \%$ chose psychological methods, $7.7 \%$ chose physical methods, $31.9 \%$ chose a combination of non-physical and psychological methods, $11.02 \%$ chose a combination of all methods (random use of all methods).

A bivariate analysis of region of household and type of discipline method chosen (Table 2), shows that the Northern region had the highest respondents $(19.8 \%)$ in the sample. Of the 1,615 respondents in this region, $4.3 \%$ chose to apply non-physical methods, $6.2 \%$ applied psychological methods, $2.1 \%$ applied physical methods, 6.3\% applied non-physical and psychological methods and $0.9 \%$ applied a combination of all methods. We also observed that the region with the lowest proportion of respondents is the Eastern region (5.6\%) where the most chosen discipline method by households is a combination of non-physical and psychological aggression discipline methods. A Pearson's chi-square test for 
Table 1. Model information.

\begin{tabular}{ccccc}
\hline \multicolumn{5}{c}{ Response profile } \\
Discipline method & Frequency & Percent & $\begin{array}{c}\text { Cumulative } \\
\text { Frequency }\end{array}$ & $\begin{array}{c}\text { Cumulative } \\
\text { Percent }\end{array}$ \\
\hline Non-physical methods & 1877 & 23.01 & 1877 & 23.01 \\
Psychological methods & 2153 & 26.40 & 4030 & 49.41 \\
Physical methods & 625 & 7.66 & 4655 & 57.07 \\
Non-physical and Psychological methods & 2602 & 31.90 & 7257 & 88.98 \\
All methods & 899 & 11.02 & 8156 & 100.00 \\
\hline
\end{tabular}

In modeling category probabilities, Type of Discipline = Random use of "all three methods" served as the reference category.

Table 2. Region of household by type of discipline method.

\begin{tabular}{ccccccc}
\hline & \multicolumn{5}{c}{ Type of discipline method } & \multirow{2}{*}{ Region } \\
\cline { 2 - 5 } & $\begin{array}{c}\text { Non-physical } \\
\text { methods } \\
\%\end{array}$ & $\begin{array}{c}\text { Psychological } \\
\text { methods } \\
\%\end{array}$ & $\begin{array}{c}\text { Physical } \\
\text { methods } \\
\%\end{array}$ & $\begin{array}{c}\text { Non-physical and } \\
\text { Psychological } \\
\text { methods } \%\end{array}$ & $\begin{array}{c}\text { All } \\
\text { methods } \\
\%\end{array}$ & Total (\%) \\
Western & 1.63 & 1.21 & 0.29 & 1.94 & 0.72 & $473(5.80 \%)$ \\
Central & 4.19 & 2.99 & 0.65 & 3.98 & 2.80 & $1192(14.62 \%)$ \\
Greater Accra & 1.31 & 1.28 & 0.45 & 1.88 & 1.35 & $511(6.27 \%)$ \\
Volta & 1.15 & 1.61 & 0.59 & 1.67 & 1.01 & $491(6.02 \%)$ \\
Eastern & 1.20 & 1.25 & 0.50 & 1.79 & 0.86 & $457(5.6 \%)$ \\
Asante & 1.30 & 1.85 & 0.33 & 2.43 & 1.05 & $568(6.96 \%)$ \\
Brong Ahafo & 1.25 & 1.18 & 0.38 & 2.48 & 0.60 & $480(5.89 \%)$ \\
Northern & 4.33 & 6.20 & 2.10 & 6.33 & 0.85 & $1615(19.8 \%)$ \\
Upper East & 2.21 & 5.21 & 1.25 & 4.67 & 0.86 & $1158(14.2 \%)$ \\
Upper West & 4.44 & 3.62 & 1.12 & 4.74 & 0.93 & $1211(14.85 \%)$ \\
Total & 1877 & 2153 & 625 & 2602 & 899 & 8156 \\
& $23.01 \%$ & $26.4 \%$ & $7.66 \%$ & $31.9 \%$ & $11.02 \%$ & $100 \%$ \\
\hline
\end{tabular}

association between these variables show that the region of household was significantly associated with the type of discipline method chosen $\left(\chi^{2}=540.30, p<\right.$ 0.0001 ) suggesting that, the type of disciplinary method chosen by households varies significantly across the regions.

The bivariate analysis (Table 3 ) results again show that in all cases, household heads with no education were in the majority in the choice of all the different types of discipline methods with the exception of random use of discipline methods, where household heads with Middle/JSS were highest (6.2\%): Non-physical discipline methods-12.2\%, Psychological discipline methods-16.9\%, Physical discipline methods-5.4\%, Non-physical and psychological methods-17.3\%. A Pearson's chi-square test for association shows that the level of education of the household head is significantly associated with the type of discipline method 
Table 3. Characteristics of household by type of discipline method.

\begin{tabular}{|c|c|c|c|c|c|c|}
\hline $\begin{array}{l}\text { Variables (chi-square and } \\
\qquad p \text {-value) }\end{array}$ & & $\begin{array}{c}\text { Non-physical } \\
\text { methods } \\
\%\end{array}$ & $\begin{array}{l}\text { Psychological } \\
\text { methods } \\
\%\end{array}$ & $\begin{array}{l}\text { Physical } \\
\text { methods } \\
\%\end{array}$ & $\begin{array}{l}\text { Non-physical and } \\
\text { psychological } \\
\text { method } \%\end{array}$ & All methods (\%) \\
\hline \multirow{5}{*}{$\begin{array}{c}\text { Wealth Index } \\
\text { Chi-square }=230.63 \\
p<0.0001\end{array}$} & Poorest & 9.31 & 12.16 & 3.73 & 13.27 & $199(2.44 \%)$ \\
\hline & Second & 4.77 & 5.10 & 1.66 & 6.44 & $191(2.34 \%)$ \\
\hline & Middle & 3.92 & 3.51 & 0.91 & 4.90 & $169(2.07 \%)$ \\
\hline & Fourth & 2.91 & 3.05 & 0.88 & 4.16 & $169(2.07 \%)$ \\
\hline & Richest & 2.11 & 2.57 & 0.49 & 3.14 & $171(2.1 \%)$ \\
\hline \multirow{4}{*}{$\begin{array}{c}\text { Education of } \\
\text { household head } \\
\text { Chi-square }=1164.92 \\
p<0.0001\end{array}$} & None & 12.21 & 16.87 & 5.37 & 17.26 & $41(0.5 \%)$ \\
\hline & Primary & 2.76 & 3.08 & 0.8 & 4.14 & $225(2.76 \%)$ \\
\hline & Middle/JSS & 7.04 & 3.79 & 1.21 & 8.73 & $502(6.15 \%)$ \\
\hline & Secondary+ & 1.01 & 2.66 & 0.28 & 1.77 & $131(1.61 \%)$ \\
\hline \multirow{10}{*}{$\begin{array}{c}\text { Ethnicity of } \\
\text { household head } \\
\text { Chi-squared }= \\
p<0.0001\end{array}$} & Akan & 7.36 & 6.06 & 1.43 & 9.51 & $417(5.11 \%)$ \\
\hline & Ga/Dangme & 1.04 & 0.99 & 0.4 & 1.04 & $59(0.72 \%)$ \\
\hline & Ewe & 1.97 & 2.32 & 0.64 & 2.67 & $125(1.53 \%)$ \\
\hline & Guan & 0.86 & 0.86 & 0.44 & 1.32 & $33(0.4 \%)$ \\
\hline & Gruma & 1.51 & 1.95 & 0.66 & 2.04 & $38(0.47 \%)$ \\
\hline & Mole Dagbani & 7.97 & 11.39 & 3.16 & 12.03 & $163(2.00 \%)$ \\
\hline & Grusi & 1.43 & 1.64 & 0.59 & 1.78 & $35(0.43 \%)$ \\
\hline & Mande & 0.25 & 0.61 & 0.13 & 0.71 & $9(0.11 \%)$ \\
\hline & Non-Ghanaian & 0.37 & 0.39 & 0.12 & 0.48 & $13(0.16 \%)$ \\
\hline & Others & 0.26 & 0.18 & 0.07 & 0.32 & 7 (0.09\%) \\
\hline \multirow{3}{*}{$\begin{array}{c}\text { Gender of household head } \\
\text { Chi-square }=4.64 \\
p<0.3258\end{array}$} & Male & 17.58 & 20.35 & 5.85 & 23.79 & $679(8.33 \%)$ \\
\hline & Female & 5.43 & 6.04 & 1.81 & 8.12 & $220(2.7 \%)$ \\
\hline & Christian & 12.84 & 12.78 & 3.32 & 16.82 & $657(8.06 \%)$ \\
\hline \multirow{3}{*}{$\begin{array}{l}\text { Religion of household head } \\
\text { Chi-square }=212.067 \\
p<0.0001\end{array}$} & Moslem & 5.90 & 7.69 & 2.50 & 8.34 & $112(1.37 \%)$ \\
\hline & Traditional & 2.92 & 4.27 & 1.36 & 4.65 & $71(0.87 \%)$ \\
\hline & other & 1.36 & 1.67 & 0.48 & 2.10 & $59(0.72 \%)$ \\
\hline \multirow{4}{*}{$\begin{array}{l}\text { Age-group of household head } \\
\text { chi-square }=75.2124 \\
p<0.0001\end{array}$} & $15-21$ years & 0.09 & 0.10 & 0.04 & 0.16 & $9(0.11 \%)$ \\
\hline & $22-40$ years & 7.58 & 8.86 & 2.66 & 10.96 & $380(4.66 \%)$ \\
\hline & $41-60$ years & 10.05 & 11.82 & 3.11 & 14.31 & $410(5.03 \%)$ \\
\hline & 61 years & 5.30 & 5.62 & 1.85 & 6.47 & $100(1.23 \%)$ \\
\hline \multirow{3}{*}{$\begin{array}{l}\text { Number of children } \\
\text { in household } \\
\text { chi-square }=25.7845 \\
p<0.0011\end{array}$} & 1 child & 6.68 & 7.16 & 1.90 & 9.37 & $309(3.79 \%)$ \\
\hline & 2 children & 5.87 & 7.01 & 2.07 & 8.75 & $226(2.77 \%)$ \\
\hline & $3+$ & 10.46 & 12.22 & 3.69 & 13.78 & $364(4.46 \%)$ \\
\hline
\end{tabular}

used $\left(\chi^{2}=1164, p<0.0001\right)$. This means the use of the different discipline methods varies significantly at the different levels of education of the household 
head.

With respect to which ethnicity groupings chose to apply physical discipline methods the most, the results show that household heads from the Mole Dagbani group were in the majority (3.2\%) followed by Akan household heads (1.4\%). Again, a Pearson chi-square test for ethnicity $\left(\chi^{2}=358.85, p<0.0001\right)$ indicated a significant association between ethnicity of head and type of discipline method chosen.

The results further show that, households in the lowest wealth index quintile have the highest proportion of heads who chose to apply physical discipline (3.7\%) as correctional measures with households in the highest wealth index quintile having the lowest proportion of heads who chose physical discipline. A Pearson chi-square test $\left(\chi^{2}=230.64, p<0.0001\right)$ indicated the association between the two variables was significant.

The results furthermore show the proportion of male headed households (5.9\%) who choose to apply physical discipline methods is higher than the proportion of female headed households who choose to apply physical discipline (1.8\%). The Pearson test of association between sex of head and type of discipline method chosen, in this instance was not significant $\left(\chi^{2}=4.64, p<0.3258\right)$.

Additionally, the Table shows that there is a significant association between religion of household head and type of discipline method chosen $\left(\chi^{2}=212.07, p\right.$ $<0.0001)$. Similarly, the age-group of household head and the number of children aged $2-14$ in a household have significant association with the type of discipline method chosen for application in the two households. In conclusion, using the bivariate analysis, 7 out of the 9 variables indicated significant association with the response variable.

\subsection{Model Results}

\subsubsection{Likelihood of Applying Method}

Table 4 presents information on the likelihood of a household head to choose each of the discipline types under consideration. The Table shows four intercepts of equations of the different types of discipline methods simultaneously estimated with their parameter estimates and standard errors from the null model. These parameters estimates represent the log-odds of a household head choosing to apply each of the discipline methods. The response "All methods (random use of all methods or no preferred method") was set as the reference category.

The intercept estimate for the non-physical and psychological disciplinary methods category (1.0446) suggests that, the log-odds of choosing non-physical and psychological disciplinary methods in a typical region was significantly higher $(\operatorname{Pr}>|t|=0.0001)$ than that of choosing the reference category. Similarly, from the Table, the estimates for the intercepts of a household choosing to apply non-physical discipline methods is 0.6706 and that for choosing physical discipline methods, is -0.4709 . These values imply that in a typical region, the log-odds of households choosing to apply non-physical discipline methods, is higher than the log-odds of households choosing to apply physical discipline methods. 
Table 4. (a) Estimates of intercepts and standard errors of discipline methods; (b) Computed observed and predicted response probabilities.

(a)

\begin{tabular}{|c|c|c|c|c|c|c|c|c|c|}
\hline \multicolumn{10}{|c|}{ Solutions for Fixed Effects } \\
\hline Effect & Discipline types & Estimate & SE & $\mathrm{DF}$ & $\mathrm{t}$ Value & $\operatorname{Pr}>|t|$ & Alpha & Lower & Upper \\
\hline $\begin{array}{c}\text { Intercept } \\
(\mathrm{k}=2)\end{array}$ & $\begin{array}{c}\text { Non-physical and } \\
\text { Psychological } \\
\text { methods }\end{array}$ & 1.0446 & 0.1654 & 36 & 6.31 & $<0.0001$ & 0.05 & 0.7091 & 1.3802 \\
\hline $\begin{array}{l}\text { Intercept } \\
(\mathrm{k}=3)\end{array}$ & $\begin{array}{c}\text { Non-physical } \\
\text { methods }\end{array}$ & 0.6706 & 0.1587 & 36 & 4.23 & 0.0002 & 0.05 & 0.3488 & 0.9923 \\
\hline $\begin{array}{l}\text { Intercept } \\
(\mathrm{k}=4)\end{array}$ & Physical methods & -0.4709 & 0.2132 & 36 & -2.21 & 0.0337 & 0.05 & -0.9033 & -0.0384 \\
\hline $\begin{array}{l}\text { Intercept } \\
(\mathrm{k}=5)\end{array}$ & $\begin{array}{l}\text { Psychological } \\
\text { methods }\end{array}$ & 0.7718 & 0.1953 & 36 & 3.95 & 0.0003 & 0.05 & 0.3757 & 1.1678 \\
\hline
\end{tabular}

(b)

\begin{tabular}{|c|c|c|c|c|}
\hline$k$ & Type of discipline method & $n$ & $\begin{array}{l}\text { Observed sample } \\
\text { response probability } \\
\qquad \pi_{k}=\frac{n}{8156}\end{array}$ & $\begin{array}{c}\text { Computed sample } \\
\text { response probability } \\
\text { (Predicted Probability) } \\
\pi_{c i j}=\frac{\exp \left(\eta_{c i j}\right)}{1+\sum_{c=1}^{C-1} \exp \left(\eta_{c i j}\right)}(3)\end{array}$ \\
\hline 1 & $\begin{array}{l}\text { All methods (random use of } \\
\text { any methods) }\end{array}$ & 899 & 0.1102 & 0.1166 \\
\hline 2 & $\begin{array}{l}\text { Non-physical and psychological } \\
\text { discipline methods }\end{array}$ & 2602 & 0.3190 & 0.3310 \\
\hline 3 & Non-physical methods & 1877 & 0.2301 & 0.2277 \\
\hline 4 & Physical discipline methods & 625 & 0.0766 & 0.0727 \\
\hline \multirow[t]{2}{*}{5} & Psychological methods & 2153 & 0.2639 & 0.2520 \\
\hline & Total & 8156 & 1.000 & \\
\hline
\end{tabular}

Again, the log-odds of choosing physical discipline is lesser than that of randomly choosing the reference category. Furthermore, the log-odds of a household choosing psychological aggression discipline methods for correction is about 0.8 times higher $(0.7718)$ than randomly choosing the reference category. All these intercepts are significant.

The results (Table 4(b)) imply that, the most likely discipline methods a household will choose for correction of child misbehaviour is a combination of non-physical and psychological aggression discipline methods with a probability of 0.3310 in contrast to the reference category (random use of methods). This suggests that, despite the high proportion (48\%) of households [16], who indicated their approval for use of physical discipline for appropriate child upbringing, only $33 \%$ in actual practice chose to apply the method. The table also shows that computed predicted probability values using Equation (3) appear to be close to the observed response probabilities indicating the average response rate in the 
data was just about equal to the average predicted probability.

This finding seems to contradict the observed increase in the use of physical discipline methods in the MICS 4 descriptive analysis reports [9] [10]. This finding also dispels the assumptions about the traditional perception that physical discipline is the main disciplinary practice applied for Ghanaian children. In addition, the results show that Ghanaian households, in practice, apply a variety of discipline methods. Again, the finding could mean a change in attitude of Ghanaian parents in respect of choice of child disciplinary practices but not Ghanaian cultural norms. It also appears parents' responses seem to reflect desirability bias rather than actual behaviour. By choosing more non-physical discipline alternatives it looks like the Ghanaian parent is distancing itself from a commonly held practice of physical discipline towards the application of non-physical discipline methods. This is noteworthy given that previous studies [9] [10] indicated high application of physical discipline methods.

\subsubsection{Likelihood of Applying a Discipline Method across Regions}

Table 5 presents information on whether the likelihoods of choosing these methods vary across regions and whether there is a relationship between region of household and choice of discipline method. The results show an intercept estimate of 0.2562 and standard error of 0.1216 with a $p$-value of 0.0175 for choice of non-physical and psychological methods. These figures mean there is significant variation across the regions in the log-odds of choosing non-physical and psychological methods relative to the reference category. With respect to the likelihood of choosing non-physical methods, the results (intercept $=0.2319$, std error $=0.2000, p$-value $=0.0189)$ indicate variation of choice across the regions. Similarly, the estimates for physical discipline (intercept $=0.4193$, std error $=$ $0.1995, p$-value $=0.0178)$, psychological aggression discipline (intercept $=$ 0.3620 , std error $=0.1691, p$-value $=0.0161)$ indicate variation of choices across the regions. In all these cases, the $z$ tests suggest significant variability in the choice of the methods between regions.

The findings suggest that the region in which parents dwell appears to influence or affect the likelihood of choosing particular discipline types. This could mean that the region in which families dwell constitutes some context that either supports or discourages the use of specific discipline types. What is not clear

Table 5. Covariance parameter estimates (unconditional model).

\begin{tabular}{ccccccc}
\hline \multicolumn{7}{c}{ Covariance Parameter Estimates } \\
\hline Cov Parm & Subject & Group & Estimate & SE & Z Value & Pr $>$ Z \\
\hline \multirow{2}{*}{ Intercept } & Region & $\begin{array}{c}\text { Non-physical and } \\
\text { Psychological methods }\end{array}$ & 0.2562 & 0.1216 & 2.11 & 0.0175 \\
Intercept & Region & Non-physical methods & 0.2319 & 0.1117 & 2.08 & 0.0189 \\
Intercept & Region & Physical methods & 0.4193 & 0.1995 & 2.10 & 0.0178 \\
Intercept & Region & Psychological methods & 0.3620 & 0.1691 & 2.14 & 0.0161 \\
\hline
\end{tabular}


however, is whether these effects could be attributed to the cultural or social economic differences within the regions. Additionally, the results show that choosing physical discipline methods in contrast to the reference category is favored most among households living in the Northern region, followed by the Eastern and Volta regions and favored least by households in the Central region after controlling for household characteristics.

With respect to choosing a combination of non-physical and psychological discipline methods, Brong Ahafo region has the highest likelihood, followed by the North and Upper East regions with the Eastern region having the least likelihood of choosing these methods. Similarly, Upper East, Central and Northern regions have the highest propensity to choose psychological aggression discipline methods with Greater Accra region having the least likelihood.

Table 6 shows the important influential covariates on the different types of the discipline methods under discussion. Table 6, indicates generally, that the log-odds of choosing physical discipline methods in contrast to the reference category, have more positive predictor associations [(ethnicity of household head (0.0036), wealth index of household (0.1152), and religion of household head (0.0261), age-group of household head (0.1464) and number of children in household (0.0389)] than the log-odds of choosing the other discipline methods. The more positive coefficients of the predictors for this category of discipline method means that the category has a higher chance of being chosen in contrast to the reference category and also than the other category of discipline methods with fewer positive coefficients.

Table 6 further shows the log-odds of choosing a combination of non-physical and psychological methods in contrast to the reference category has the second highest number of positive predictors associations [(ethnicity of household of head (0.0048), wealth index of household (0.1209), religion of household head (0.0082), age-group of household head (0.1730)] followed by the log-odds of choosing non-physical discipline methods and psychological aggression discipline methods with three positive covariates associations each (ethnicity of household head, wealth index of household and age-group of household head.

Again, Table 6 shows that the educational level of the household head, the wealth index of the household and the age-group of household head, have statistically significant effects on a household's choice of all the different categories of discipline methods. On the other hand, ethnicity of household head, sex of household head, religion of household head and number of children, appear not to be important factors in the choice of the different category of discipline methods

\subsubsection{Covariate Effect on Choice of Specific Discipline Methods Non-physical and psychological disciplinary methods}

The results show that when it comes to choosing non-physical and psychological discipline methods, the most influential predictors are educational level 
Table 6. Effect of level 1 significant predictors on discipline types.

\begin{tabular}{|c|c|c|c|c|c|c|c|c|c|}
\hline Effect & Discipline type & Estimate & SE & DF & t Value & $\operatorname{Pr}>|t|$ & Alpha & Lower & Upper \\
\hline Intercept & Non-physical and Psychological methods & 2.4548 & 0.3400 & 36 & 7.22 & $<0.0001$ & 0.05 & 1.7652 & 3.1445 \\
\hline Intercept & Non-physical methods & 2.0976 & 0.3509 & 36 & 5.98 & $<0.0001$ & 0.05 & 1.3860 & 2.8091 \\
\hline Intercept & Physical methods & 1.5431 & 0.4463 & 36 & 3.46 & 0.0014 & 0.05 & 0.6380 & 2.4482 \\
\hline Intercept & Psychological methods & 2.4522 & 0.3566 & 36 & 6.88 & $<0.0001$ & 0.05 & 1.7289 & 3.1755 \\
\hline Head_Education & Non-physical and Psychological methods & -0.9007 & 0.0502 & 8088 & -17.91 & $<0.0001$ & 0.05 & -0.9993 & -0.8021 \\
\hline Head_Education & Non-physical methods & -0.8827 & 0.0524 & 8088 & -16.86 & $<0.0001$ & 0.05 & -0.9853 & -0.7801 \\
\hline Head_Education & Physical methods & -1.2470 & 0.0710 & 8088 & -17.58 & $<0.0001$ & 0.05 & -1.3861 & -1.1080 \\
\hline Head_Education & Psychological methods & -1.0364 & 0.0522 & 8088 & -19.82 & $<0.0001$ & 0.05 & -1.1389 & -0.9339 \\
\hline Head_Ethnicity & Non-physical methods & 0.0046 & 0.0061 & 8088 & 0.73 & 0.4660 & 0.05 & -0.00787 & 0.01719 \\
\hline Head_Ethnicity & Physical methods & 0.0039 & 0.0074 & 8088 & 0.53 & 0.5962 & 0.05 & -0.01069 & 0.01861 \\
\hline Head_Ethnicity & Psychological methods & 0.0024 & 0.0064 & 8088 & 0.38 & 0.7029 & 0.05 & -0.01022 & 0.01516 \\
\hline HHold_Windex & Non-physical and Psychological methods & 0.1209 & 0.0377 & 8088 & 3.20 & 0.0014 & 0.05 & 0.04679 & 0.1949 \\
\hline HHold_Windex & Non-physical methods & 0.0819 & 0.0392 & 8088 & 2.09 & 0.0370 & 0.05 & 0.004958 & 0.1589 \\
\hline HHold_Windex & Physical methods & 0.1152 & 0.0532 & 8088 & 2.16 & 0.0307 & 0.05 & 0.01074 & 0.2196 \\
\hline HHold_Windex & Psychological methods & 0.1768 & 0.0397 & 8088 & 4.45 & $<0.0001$ & 0.05 & 0.09892 & 0.2546 \\
\hline Head_Sex & Non-physical and Psychological methods & -0.0426 & 0.0983 & 8088 & -0.43 & 0.6646 & 0.05 & -0.2354 & 0.1501 \\
\hline Head_Sex & Non-physical methods & -0.1671 & 0.1034 & 8088 & -1.62 & 0.1062 & 0.05 & -0.3698 & 0.03566 \\
\hline Head_Sex & Psychological methods & -0.1560 & 0.1028 & 8088 & -1.52 & 0.1290 & 0.05 & -0.3575 & 0.04543 \\
\hline Head_Religion & Non-physical and Psychological methods & 0.0082 & 0.0493 & 8088 & 0.17 & 0.8677 & 0.05 & -0.08843 & 0.1049 \\
\hline Head_Religion & Non-physical methods & -0.0655 & 0.0517 & 8088 & -1.27 & 0.2048 & 0.05 & -0.1669 & 0.03578 \\
\hline Head_Religion & Physical methods & 0.0261 & 0.0640 & 8088 & 0.41 & 0.6836 & 0.05 & -0.09944 & 0.1516 \\
\hline Head_Religion & Psychological methods & -0.0090 & 0.0509 & 8088 & -0.18 & 0.8585 & 0.05 & -0.1090 & 0.0908 \\
\hline Head_AgeGroup & Non-physical and Psychological methods & 0.1730 & 0.0588 & 8088 & 2.94 & 0.0033 & 0.05 & 0.0576 & 0.2883 \\
\hline Head_AgeGroup & Non-physical methods & 0.2708 & 0.0611 & 8088 & 4.43 & $<0.0001$ & 0.05 & 0.1510 & 0.3905 \\
\hline Head_AgeGroup & Physical methods & 0.1464 & 0.0766 & 8088 & 1.91 & 0.0561 & 0.05 & -0.0038 & 0.2965 \\
\hline Head_AgeGroup & Psychological methods & 0.1671 & 0.0606 & 8088 & 2.76 & 0.0059 & 0.05 & 0.0482 & 0.2859 \\
\hline Num_Children & Non-physical and Psychological methods & -0.0454 & 0.0499 & 8088 & -0.91 & 0.3627 & 0.05 & -0.1432 & 0.0523 \\
\hline Num_Children & Non-physical methods & -0.0179 & 0.0520 & 8088 & -0.35 & 0.7298 & 0.05 & -0.1201 & 0.0840 \\
\hline Num_Children & Physical methods & 0.0389 & 0.0676 & 8088 & 0.58 & 0.5646 & 0.05 & -0.0936 & 0.1716 \\
\hline Num_Children & Psychological methods & -0.0015 & 0.0517 & 8088 & -0.03 & 0.9760 & 0.05 & -0.1031 & 0.0999 \\
\hline
\end{tabular}

of household head $(-0.9007, p<0.0001)$, wealth index of household $(0.1209, p<$ $0.0014)$, and age-group of household head $(0.1730, p<0.0033)$. These predictors have significant effects in predicting the log-odds of a household choosing methods in this category. 
The coefficients of wealth index of household (0.1209), and age-group of household head (0.1730) are positive indicating households with increasing wealth index and increasing age-group of household's head, have higher predicted log-odds of choosing non-physical and psychological methods for discipline in contrast to choosing to apply the reference category.

In other words, if the wealth index of a household increases by one unit, the corresponding change in the log-odds is 0.12 . Similarly, a unit increase in the age-group of the head of household increases the log-odds of choosing a method in this category by 0.17 . The negative coefficient for educational level of household head means that as the household head's educational level increases there will be a decrease in the probability to choose non-physical and psychological discipline methods in contrast to the reference category (random use of all methods).

\section{Non-physical discipline methods}

In terms of applying non-physical discipline methods, the predictors, educational level of household head $(-0.8827, p<0.001)$ and age-group of household head $(0.2708, p<0.0001)$ are highly significant with wealth index of household $(0.08191, p<0.0370)$ marginally significant. With regards to the educational level of household head, the log-odds of a household head choosing this category of discipline as against the reference category, decrease by 0.8827 units $(-0.8827)$ for household head with low education compared to household heads with high education. The odds ratio indicates that predicted odds of household head with low education choosing this method compared to the reference category is 0.406 $\left(e^{-0.8827}\right)$ times the odds of household heads with high education. In other words the odds of choosing this method in contrast to the reference is reduced by about $59.4 \%(1-0.406=0.594)$ for household heads with low education compared with households heads with high education holding all other predictors constant.

\section{Physical discipline methods}

With respect to choosing physical discipline methods, the covariates educational level of household head $(-1.2470, p<0.001)$, age-group of household head $(0.1464, p<0.0561)$, wealth index of household $(0.1152, p<0.037)$ have significant effects in predicting the log-odds of choosing this method, compared to randomly choosing any method (reference category). Again, the negative coefficient of the predictor, educational level of household head indicates household heads with increasing educational level will have lower predicted log-odds of choosing to apply physical discipline methods only.

\section{Psychological aggression discipline methods}

In terms of psychological aggression discipline methods, education level of household head $(-1.0364, p<0.0001)$ and wealth index of household $(0.1768, p$ $<0.0001)$ are highly significant in predicting their choice, with age-group of household head $(0.1671, p<0.0059)$ being marginally significant. The negative estimate of educational level of household head means households' heads with increasing educational level will have a lower predicted log-odds of choosing to 
apply psychological aggression discipline methods.

Overall, our results showed that, the significant covariates that influence a household's likelihood to choose each of the discipline methods were; educational level and age-group of the household head and wealth index of the household. These three covariates all have significant associations with all the different types of discipline methods with the exception of the use of non-physical discipline method where age-group of the household head is not significant. Whereas educational level of the household head has a negative influence, household's wealth index and the age-group of household head have positive influence on the likelihood of choosing to apply all the different categories of discipline methods.

A number of studies have shown that socio-economically advantaged and disadvantaged parents differ in the quality and quantity of their interactions with children. This observation could be the result economic hardship, emotional stress, and lower access to information and services that often accompany low income among others. For example, Pinderhughes, Dodge and Bates in 2000, found significant association between lower socio-economic status of families and application of harsher discipline methods [17]. Discipline strategies differ by family background such that parents with lower education and income levels tend to apply physical discipline more often, and apply non-physical forms of discipline less often, than parents of higher socio-economic status. Gershoff, in 2002 , concluded that mothers with low education are likely to believe that physical discipline prepares children for the larger world that will expect them to obey and not resist. "These mothers may not be aware of its negative effects on children's behaviour and their psychological and social well-being such as showing higher rates of criminal activity, perpetration of partner assault, abuse against one's own children and depression" [18] [19] [20].

Choosing to apply physical discipline on children has been supported by religious affiliations and beliefs of many [21]. In particular, conservative protestant affiliation and conservative religious beliefs are associated with more frequent use of physical discipline [22]. The findings of this study do not support the above observation.

Parents' ethnicity is considered as a tradition built on nationality, language, and culture. A number of studies have been conducted to find out if ethnicity is a determinant of the application of physical discipline methods [23] or a relationship exists between ethnicity and different types of discipline methods [24]. The results of these studies however, are inconclusive and largely contradictory [25]. Some studies, however, have found parents' choice of physical discipline methods in certain ethnic groups more often than in other ethnic groups [26]. Where such variances exist, the effects are minimal. The findings of our study indicate ethnicity has no significant relationship with the choice of physical discipline methods, thus supporting earlier findings. The findings, however, show ethnicity has significant relationship with households' choice of non-physical discipline and psychological aggression discipline methods. The effect of a par- 
ents' ethnicity on the type of discipline method likely to be chosen for application has been found to vary between and within ethnic groups. Parke and Buriel in 1998, found that this variation is the result of the influenced of varying income levels within and between the groups [27].

\subsubsection{Regional Effect on Choice of Specific Discipline Methods}

Aside individual characteristics known to influence individual action and behavior, research also shows that the surroundings of the individual such as social class, ethnic or religious composition of a location or the context in which the individual dwells affect the individual behavior and actions. Burbank in 1995, observed that "Contextual effects do not come about as a result of composition alone, but also from individual learning and acting in an environment with informational bias". In Burbank's model, "the individual cognition is a product of social experience and different environments will stimulate difference political context" [28].

Studies have also shown that the characteristics of a particular geographical location such as its culture and the class composition of a community is known to affect the orientation of individuals who dwells in such geographical locations. This happens as a result of social interaction. The difference in geographical location is also known to work differently in the conditions experienced by individuals and may determine the kinds of action or behavior. To answer the question on whether choice of a discipline method vary across the regions, Table 7 shows the regional effects on the choice of each type of discipline method when household background variables are controlled.

\section{Non-physical and psychological disciplinary methods}

When household background variables are controlled, the point estimates and $p$ values associated with Brong Ahafo region (0.3217, $p<0.0249)$ followed by Northern region $(0.2822, p<0.0380)$ and Upper East $(0.1895, p<0.1679)$ regions have the highest positives values (Table 7). This suggests that across the regions, the log-odds of households choosing non-physical and psychological discipline methods is highest in the Brong Ahafo region followed by the Northern and Upper East regions than in households in the other regions. The region with the lowest log-odds of household choosing non-physical and psychological discipline method is the Central region $(-0.4596, p<0.0002)$.

\section{Non-physical discipline methods}

To choose non-physical discipline methods, Table 7 again shows that across the regions, the point estimates of Upper West $(0.3092, p<0.019)$ Western $(0.265, p<0.0584)$ and Northern $(0.2292, p<0.0798)$ regions are the highest; suggesting households in Upper West, followed by Western and Northern regions have higher log-odds of choosing non-physical discipline methods than households in the other regions. The point estimate for Upper West region, is significant while the estimates for Western, Northern and the other regions are not significant. The Volta region $(-0.2357, p<0.095)$ has the smallest point estimate and is the region with the lowest log-odds of households choosing 
non-physical discipline methods.

\section{Physical discipline methods}

The results show that households in the Northern region have the highest point estimate of 0.4358 and a significant $p$-value of 0.0092 . This implies households in the region have the highest log-odds of choosing physical discipline methods, followed by households in the Eastern $(0.2860, p<0.1337)$ and Volta $(0.1984, p$ $<0.2798)$ regions respectively. The region with the lowest log-odds of households choosing physical discipline methods is the Central $(-0.6021, p<0.0008)$.

Psychological aggression methods

In terms of choosing psychological aggression methods, Upper East $(0.5608, p$ $<0.0003)$, followed by Central $(0.4900, p<0.0007)$ and Northern $(0.4758, p<$ $0.0018)$ are the regions with the highest point estimates and significant $p$-values (Table 7). This suggests that these regions have higher log-odds of households choosing psychological aggression methods than households in the other regions. Households in Greater Accra have the least likelihood of choosing psychological methods.

Generally, the results show significant variations across the regions in the log-odds of choosing non-physical and psychological methods relative to the reference category. Overall, the log-odds of a household choosing non-physical discipline methods is higher than the log-odds of choosing physical discipline methods. Again, the log-odds of a household specifically choosing psychological aggression methods is 0.8 times higher than randomly choosing any method (reference category). The average response rate for each type of discipline method in the data is just about equal to the average predicted probability as the observed probabilities are close to the predicted probabilities. In all the regions, the use of physical discipline methods in contrast to the reference category was higher than the use of the other discipline methods.

Table 7. Covariance parameter estimates for regional effects.

\begin{tabular}{cccccccccc}
\hline & \multicolumn{2}{c}{$\begin{array}{c}\text { Non-physical and } \\
\text { psychological }\end{array}$} & \multicolumn{2}{c}{ Non-physical } & \multicolumn{2}{c}{ Physical } & \multicolumn{2}{c}{ Psychological } \\
\hline Region & Estimate & $P$-value & Estimate & $P$-value & Estimate & $P$-value & Estimate & $P$-value \\
\hline Ashanti & 0.0635 & 0.6300 & -0.2197 & 0.2672 & -0.2197 & 0.2672 & 0.0553 & 0.7207 \\
Brong Ahafo & 0.3217 & 0.0249 & 0.0201 & 0.8840 & -0.0141 & 0.9420 & -0.1105 & 0.5058 \\
Central & -0.4596 & 0.0002 & -0.0459 & 0.6856 & -0.6021 & 0.0008 & 0.4900 & 0.0007 \\
Eastern & -0.0293 & 0.8100 & -0.1330 & 0.3214 & 0.2860 & 0.1337 & -0.0907 & 0.5750 \\
Accra & -0.2513 & 0.0840 & 0.0201 & 0.8840 & 0.0169 & 0.9307 & -0.3901 & 0.0216 \\
Northern & 0.2822 & 0.0380 & 0.2292 & 0.0798 & 0.4358 & 0.0092 & 0.4758 & 0.0018 \\
Upper East & 0.1895 & 0.1679 & -0.1914 & 0.1483 & 0.1819 & 0.2917 & 0.5608 & 0.0003 \\
Upper West & 0.0603 & 0.6558 & 0.3092 & 0.019 & 0.0603 & 0.6558 & 0.0296 & 0.8469 \\
Volta & -0.2522 & 0.0777 & -0.2357 & 0.0950 & 0.1984 & 0.2798 & -0.0130 & 0.9346 \\
Western & 0.1024 & 0.4698 & 0.2650 & 0.0584 & -0.1194 & 0.5544 & -0.0827 & 0.6155 \\
\hline
\end{tabular}




\subsubsection{Model Assessment}

Table 8(a) shows the classification results of our model. The initial model with no predictors, classified the types of discipline methods chosen by households with an overall percentage accuracy of $33.9 \%$. Table 8 shows the classification results of applying the final model with the significant predictors. The Table indicated that the model can correctly classify the households who choose non-physical methods with a percentage accuracy of $27 \%$, households that chose psychological methods with accuracy of $54 \%$, households that chose a combination of non-physical and psychological discipline methods with an accuracy of $85 \%$ and those that randomly chose any method as $45 \%$. The model however, could not classify households who chose physical discipline methods. The classification in this instance was zero percent.

The overall correct classification rate of the final model to classify cases of type of discipline method chosen by households was $53.69 \%$. The apparent low rate of correct classification, particularly with respect to physical discipline methods (zero percent) could be due to the fact that the number of elements in that category was too small. This means that there are still other risk factors that were not accounted for.

Table 8. (a) Model classification table without predictors; (b) Model classification table with significant predictors.

(a)

\begin{tabular}{|c|c|c|c|c|c|c|}
\hline \multirow[b]{2}{*}{ Observed } & \multicolumn{6}{|c|}{ Predicted } \\
\hline & $\begin{array}{l}\text { Non physical } \\
\text { methods }\end{array}$ & $\begin{array}{l}\text { Psychological } \\
\text { methods }\end{array}$ & $\begin{array}{l}\text { Physical } \\
\text { methods }\end{array}$ & $\begin{array}{c}\text { Non physical and } \\
\text { Psychological methods }\end{array}$ & All methods & Percent Correct \\
\hline Nonphysical methods & 337 & 412 & 0 & 974 & 154 & $18.0 \%$ \\
\hline Psychological methods & 214 & 776 & 0 & 987 & 176 & $36.0 \%$ \\
\hline Physical methods & 66 & 235 & 0 & 295 & 29 & $0.0 \%$ \\
\hline Non physical and Psychological methods & 286 & 686 & 0 & 1473 & 157 & $56.6 \%$ \\
\hline All methods & 127 & 68 & 0 & 526 & 178 & $19.8 \%$ \\
\hline Overall Percentage & $12.6 \%$ & $26.7 \%$ & $0.0 \%$ & $52.2 \%$ & $8.5 \%$ & $33.9 \%$ \\
\hline
\end{tabular}

(b)

\begin{tabular}{|c|c|c|c|c|c|c|c|}
\hline \multirow[b]{2}{*}{ Observed } & \multicolumn{7}{|c|}{ Predicted } \\
\hline & $\begin{array}{l}\text { Non physical } \\
\text { methods }\end{array}$ & $\begin{array}{l}\text { Psychological } \\
\text { methods }\end{array}$ & $\begin{array}{l}\text { Physical } \\
\text { methods }\end{array}$ & $\begin{array}{c}\text { Non physical and } \\
\text { Psychological methods }\end{array}$ & All methods & Total & Percent Correct \\
\hline Non physical methods & 508 & 331 & 0 & 906 & 132 & 1877 & $27 \%$ \\
\hline Psychological methods & 179 & 1168 & 0 & 670 & 136 & 2153 & $54 \%$ \\
\hline Physical methods & 66 & 145 & 0 & 209 & 205 & 625 & $0 \%$ \\
\hline $\begin{array}{c}\text { Non physical and } \\
\text { Psychological methods }\end{array}$ & 176 & 262 & 0 & 2124 & 43 & 2605 & $85 \%$ \\
\hline All methods & 91 & 70 & 0 & 156 & 579 & 896 & $45 \%$ \\
\hline Total & 1020 & 1976 & 0 & 4065 & 1095 & 8156 & $53.69 \%$ \\
\hline
\end{tabular}




\section{Conclusions}

This study has provided an in-depth analysis of child discipline data using a multilevel modelling approach to identify and investigate what influences the choice of discipline methods by parents. The findings indicate that obtaining the real impact on parents' choices of discipline methods goes beyond just the characteristics of the parent and household, and includes the effects of the environment in which the parent or caregiver dwells as well. Considering only a bivariate analysis which does not factor in the clustering effect of the dataset, nearly all the predictor variables (7 out of 9) showed significant associations with the response variable, a result which can be misleading. The application of the multilevel model approach effectively brought to the fore the actual relationships between the response variable and the predictor variables (taking into consideration possible clustering effect) at all the levels and hence, the real effects on parents' decision in terms of choosing what discipline methods to apply.

Specifically, the results show that, educational level, religion and age-group of household head have significant effect on household's likelihood to choose physical discipline methods whereas the wealth index of a household and ethnicity of the household head, have significant effect on households' likelihood to choose non-physical and psychological aggression methods. The results further show significant contextual effect on the differences in choices of parents at the household and regional levels. The choice of physical discipline methods by parents was consistent across household and regional levels unlike non-physical and psychological aggression methods whose application varied across the regions. Households in the Northern, Eastern and Volta regions mostly chose to apply physical discipline methods whereas in the Upper West, Western and Northern regions the most applied discipline methods were non-physical discipline methods. Psychological aggression discipline methods were predominantly chosen by households in the Upper East, Central and Northern regions.

In the light of the findings of this study, we recommend the use of multilevel models in child discipline studies as the context in which the data is collected is critical particularly if the data structure is hierarchical in nature. This approach, will account for unobserved higher level variation in the data and adjust estimated errors in the estimation of standard errors of the estimates. The approach will also prevent overstating the significance of estimated statistical relationships and uncovering of statistically significant relationships when they do not exist.

Programs should be established for parents and caregivers, and for poor families as a part of any strategy that aims to reduce the level of violence against children. Programs that identify individuals in low socio-economic groups who are at high risk for violence, and less likely to choose application of non-violent discipline methods, why they are less likely to choose these discipline measures and what targeted intervention efforts would be most effective in promoting the use of non-violent discipline should be developed. Programs to eliminate cultural norms and media influence that legitimize and glorify violence should be im- 
plemented. Programs to encourage the use of non-physical discipline methods such as time-out, positive reinforcement, as well as raising public awareness about the negative effects, and relative ineffectiveness, of physical discipline methods should be instituted.

Further research that considers the inclusion of additional covariates related to child discipline practices such as gender of the child, whether child is in a broken home, etc to achieve a model with higher rate of correct classifications should be conducted. Again, research is needed to determine the source of regional variations in the application of non-physical and psychological aggression methods and why no differences exist in the use of physical discipline across the regions.

Finally, the results of this study indicated that the risk factors associated with violence against children, in terms of child discipline, are related not only to the parent's circumstance but also the environment of the household in which the child dwells. This suggests that, the totality of the family system should be the main focus of any engagement with parents and any policy to end violence against children in Ghanaian homes.

\section{Acknowledgements}

The authors would like to thank the Ghana Statistical Service for allowing them to use the MICS4 data for this study. We also acknowledge support received from Dr. Solomon Sarpong of the University for Development Studies, Navrongo; Dr. Michael Ofori of Kumasi Technical University and Lucy Twumwaah Afriyie of the Ghana Statistical Service.

\section{Author's Contribution}

The following authors contributed to writing this paper. SKA as the lead contributor with support from ENNN and AA.

\section{Funding}

This study did not receive funding support from any person or institution.

\section{Conflicts of Interest}

The authors declare no conflicts of interest with respect to the publication of this Paper.

\section{References}

[1] Schulman, M. and Mekler, E. (1985) Bringing up a Moral Child. Addison-Wesley, Reading, PA.

[2] Forgatch, M.S., Patterson, G.R. and Skinner, M.L. (1988) A Mediational Model for the Effect of Divorce on Antisocial Behavior in Boys. In: Hetherington, E.M. and Arastech, J.D., Eds., Impact of Divorce, Single Parenting, and Step-Parenting on Children, Wiley, New York, 135-154.

[3] Bates, J.E., Deater-Deckard, K., Dodge, K.A., Lansford, J.E. and Pettit, G,S. (2003) 
The Development of Attitudes about Physical Punishment: An 8-Year Longitudinal Study. Family Psychology, 17, 351-360. https://doi.org/10.1037/0893-3200.17.3.351

[4] Coffelt, N., Forehan, R., Gaffney, C.A., Jones, D., Massari, C., Mckee, L., Olson, A.L., Roland, E. and Zens, M.S. (2007) Harsh Discipline and Child Problem Behaviors: The Roles of Positive Parenting and Gender. Journal of Family Violence, 22, 187-196. https://doi.org/10.1007/s10896-007-9070-6

[5] Evans, H., Savage, E. and Socolar, R.S. (2007) A Longitudinal Study of Parental Discipline of Young Children. Southern Medical Association, 5, 472-477. https://doi.org/10.1097/SMJ.0b013e318038fb1c

[6] Sadowski, L.S., Hunter, W.M., Bangdiwala, S.I. and Munoz, S.R. (2004) The World Studies of Abuse in the Family Environment (World SAFE): A Model of a Multi-National Study of Family Violence. Injury Control and Safety Promotion, 11, 81-90. https://doi.org/10.1080/15660970412331292306

[7] Anders, S., Birbaumer, N. and Sadowski, B. (2004) Parietal Somatosensory Association Cortex Mediates Affective Blindsight. Nature Neuroscience, 7, 33-340. https://doi.org/10.1038/nn1213

[8] UNICEF Report (2017) 300 Million Cases of Violence Against Children Ages 2 to 4 .

[9] Ghana Statistical Service (2006) 2006 Multiple Indicator Cluster Survey Report.

[10] Ghana Statistical Service (2011) 2011 Multiple Indicator Cluster Survey Report.

[11] Apt, N.A., Agbenyega, D.L. and Ame, R.K. (2012) Confronting the Challenges: Optimizing Child Rights in Ghana, Children's Rights in Ghana: Reality or Rhetoric? Mot Juste Limited, London.

[12] UNICEF (2014) Ending Violence against children: Six Strategies for Action. United Nations Children's Fund.

[13] Twum-Danso, A. (2010) Children's Perceptions of Physical Punishment in Ghana. Nuffield Foundation.

[14] Family for Every Child (2014). http://wickedproblems.web.unc.edu/files/2014/04/A_family_for_Every_Child_Sum mary_External-3_20_14.pdf

[15] Danvers and Schley (2015).

https://challengingheights.org/wp-content/uploads/2014/11/Better-Discipline-for-G hanas-Children.pdf

[16] Amoah, S.K., Nortey, E. and Alhassan, A. (2019) Child Discipline Practices in Ghanaian Homes. http://ugspace.ug.edu.gh/handle/123456789/30556 https://doi.org/10.1007/s10389-019-01079-z

[17] Pinderhughes, E., Dodge, K.A. and Bates, J.E. (2000) Discipline Responses: Influences of Parents' Socioeconomic Status, Ethnicity, Beliefs About Parenting, Stress, and Cognitive-Emotional Processes. Journal of Family Psychology, 14, 380-400. https://doi.org/10.1037/0893-3200.14.3.380

[18] Gershoff, E.T. (2002) Corporal Punishment by Parents and Associated Child Behaviour and Experiences: A Meta-Analytic and Theoritical Review. Psychological Bulletin, 128, 539-579. https://doi.org/10.1037/0033-2909.128.4.539

[19] Grogan-Kaylor, A. and Otis, M.D. (2007) The Predictors of Parental Use of Corporal Punishment. Family Relations: An Interdisciplinary. Journal of Applied Family Studies, 56, 80-91. https://doi.org/10.1111/j.1741-3729.2007.00441.x

[20] Straus, M.A. (2001) Beating the Devil out of Them; Corporal Punishment in American Families and Its Effects on Children. Transaction Publishers, New Brunswick.

[21] Kochanska, G. and Hompson, R.A. (1997) The Emergence and Development of 
Conscience in Toddlerhood and Early Childhood. In: Grusec, J.E. and Kucznski, L., Eds., Parenting and Children's Internalization of Values. A Handbook of Contemporary Theory, Wiley, New York, 53-77.

[22] Xu, Y., Farver, J.M., Bhadaha, B.R., Narang, S. and Lieber, E. (2007) Ethnic Identity, Acculturation, Parenting Beliefs, and Adolescent Adjustment: A Comparison of Asian Indian and European American Families. Merrill-Palmer Quarterly, 53, 184-215. https://doi.org/10.1353/mpq.2007.0010

[23] Betancourt, H. and Lopez, S.R. (1993) The Study of Culture, Ethnicity, and Race in American Psychology. American Psychologist, 48, 629-637. https://doi.org/10.1037/0003-066X.48.6.629

[24] Marshall, K. (2005) Chapter 4: Cultural Issues. In: Smith, A.B., Gollop, M., Taylor, N. and Marshall, K., Eds., The Discipline and Guidance of Children: Messages from Research: A Review, Wiley, New York.

[25] Smith, A.B., Gallop, M., Taylor, N.J. and Marshall, K. (2005) The Discipline and Guidance of Children: A Summary of Research. Children's Issues Centre and Office of the Children's Commissioner, Dunedin and Wellington, NZ.

[26] Loeber, R., Burke, J.D., Lahey, B.B., Winters, A. and Zera, M. (2000) Oppositional Defiant and Conduct Disorder: A Review of the Past 10 Years, Part I. Journal of the American Academy of Child \& Adolescent Psychiatry, 39, 1468-1484. https://doi.org/10.1097/00004583-200012000-00007

[27] Parke, R.D. and Buriel, R. (1998) Socialization in the Family: Ethnic and Ecological Perspectives. In: Eisenberg, N. and Damon, W., Eds., Handbook of Child Psychology: Social, Emotional, and Personality Development, Wiley, New York.

[28] Burbank, M.J. (1995) The Psychological Basis of Contextual Effects. Political Geography, 14, 621-635. https://doi.org/10.1016/0962-6298(95)00057-H 